\title{
Synthetic Peptides as Structural Maquettes of Angiotensin-I Converting Enzyme Catalytic Sites
}

\author{
Zinovia Spyranti, ${ }^{1}$ Athanassios S. Galanis, ${ }^{1}$ George Pairas, ${ }^{1}$ Georgios A. Spyroulias, ${ }^{1}$ \\ Evy Manessi-Zoupa, ${ }^{2}$ and Paul Cordopatis ${ }^{1}$
}

${ }^{1}$ Department of Pharmacy, University of Patras, GR-26504, Patras, Greece
${ }^{2}$ Department of Chemistry, University of Patras, GR-26504, Patras, Greece

Correspondence should be addressed to Georgios A. Spyroulias, g.a.spyroulias@upatras.gr and

Paul Cordopatis, pacord@upatras.gr

Received 15 January 2010; Accepted 16 March 2010

Academic Editor: Spyros Perlepes

Copyright (C) 2010 Zinovia Spyranti et al. This is an open access article distributed under the Creative Commons Attribution License, which permits unrestricted use, distribution, and reproduction in any medium, provided the original work is properly cited.

\begin{abstract}
The rational design of synthetic peptides is proposed as an efficient strategy for the structural investigation of crucial protein domains difficult to be produced. Only after half a century since the function of ACE was first reported, was its crystal structure solved. The main obstacle to be overcome for the determination of the high resolution structure was the crystallization of the highly hydrophobic transmembrane domain. Following our previous work, synthetic peptides and Zinc(II) metal ions are used to build structural maquettes of the two Zn-catalytic active sites of the ACE somatic isoform. Structural investigations of the synthetic peptides, representing the two different somatic isoform active sites, through circular dichroism and NMR experiments are reported.
\end{abstract}

\section{Introduction}

Angiotensin Converting Enzyme (ACE) catalyses the conversion of angiotensin-I (AI) to the vasoconstrictor angiotensinII (AII) [1] and inactivates the vasodilatory peptide bradykinin by removing C-terminal dipeptides [2]. The inhibition of ACE enzymatic activity against AI was considered as one of the major challenges against hypertensive disease and congestive heart failure [3]. Over the past 20 years, ACE inhibitors have presented significant cardioprotective and vasculoprotective activity, by reducing oxidative stress and inflammation in the endothelium. Moreover, ACE inhibitors have been effective in improving blood flow and flow-mediated vasodilation. Inhibition of the angiotensin converting enzyme significantly reduces cardiovascular risk in a broad range of high-risk patients $[4,5]$.

ACE is a Zinc Metallopeptidase and one of the major components of the Renin-Angiotensin System (RAS) that regulates blood pressure [6-8]. In human, ACE is expressed as a somatic isoform in endothelial, epithelial, and neuroepithelial cells and as a smaller isoform only in male germinal cells. Somatic ACE (1306 AA, $150 \mathrm{kDa}$ ) consists of two homologous domains, one at each terminal, containing zinc catalytic sites ( $\mathrm{N}$-and $\mathrm{C}$-zinc catalytic sites) [9]. The testis isoform is composed of 732 residues $(83 \mathrm{kDa})$ with the 665-residue C-terminal domain being identical to the Cterminal domain of the somatic form [10-13]. Both isoforms possess a zinc-binding domain, with the somatic isoform containing one additional high homology active site $(\mathrm{N}-$ catalytic site). ACE active sites possess the characteristic HEXXH Zn-binding motif (the two His comprise the first two Zn-ligands) and falls into the gluzincin family [14]. The third $\mathrm{Zn}$ ligand, glutamic acid, is sited 23 residues towards the enzyme C-terminal at the second characteristic sequence EAXGD [15]. The fourth zinc ligand is a water molecule.

In subsequent to our previous work [16, 17], novel synthetic peptides have been investigated as structural maquettes, in order to shed further light on the conformational characteristics of both somatic isoform catalytic site domains.

Design, peptide synthesis, and a thorough investigation of the optimal conditions in order to mimic as closely 

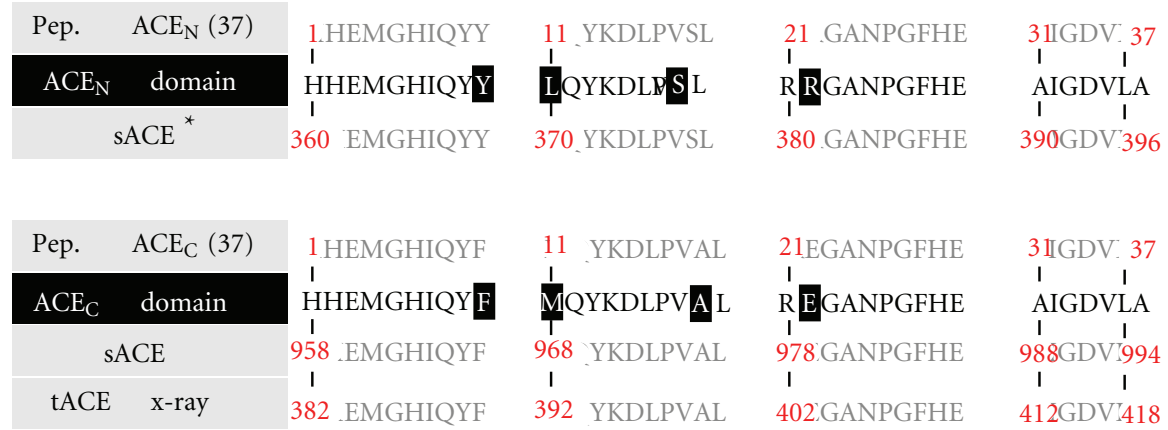

FIGURE 1: Synthetic peptide maquettes of the N- and C-active site domains of human somatic ACE (sACE). Sequence numbering of peptides, sACE, testis isoform (tACE) and crystal structures domains. The different residues among the two sequences are highlighted.

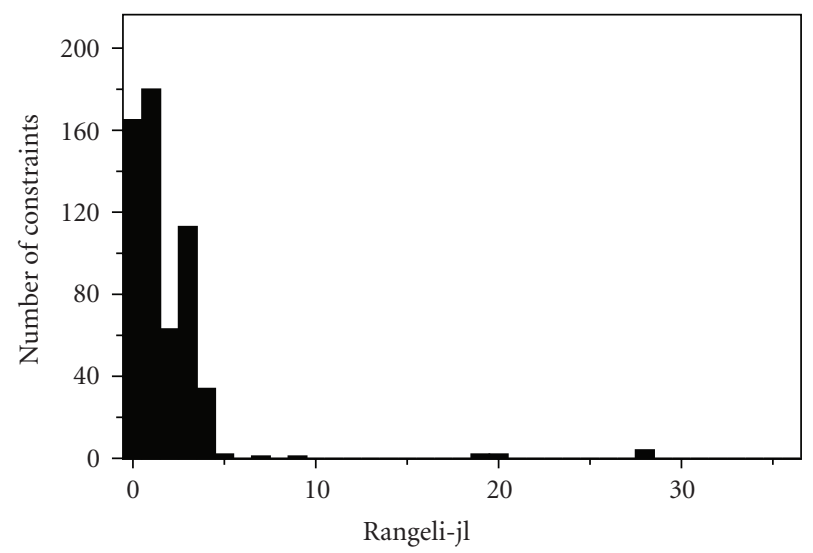

(a)

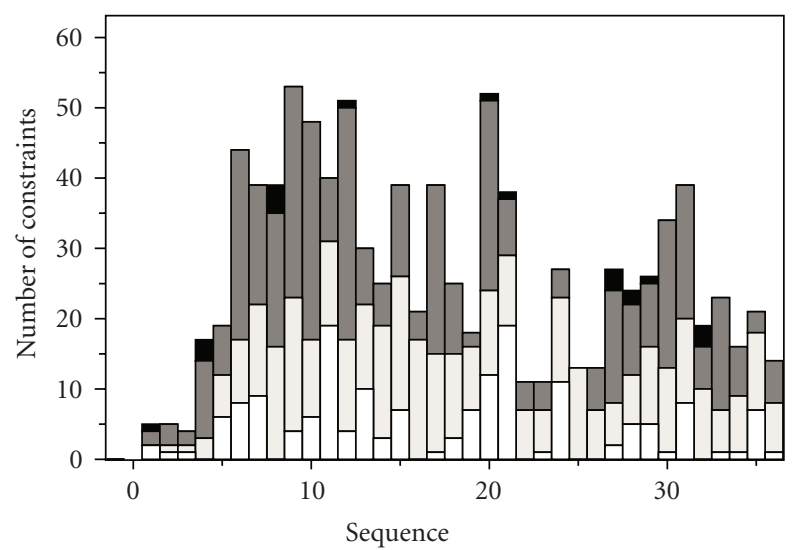

(b)

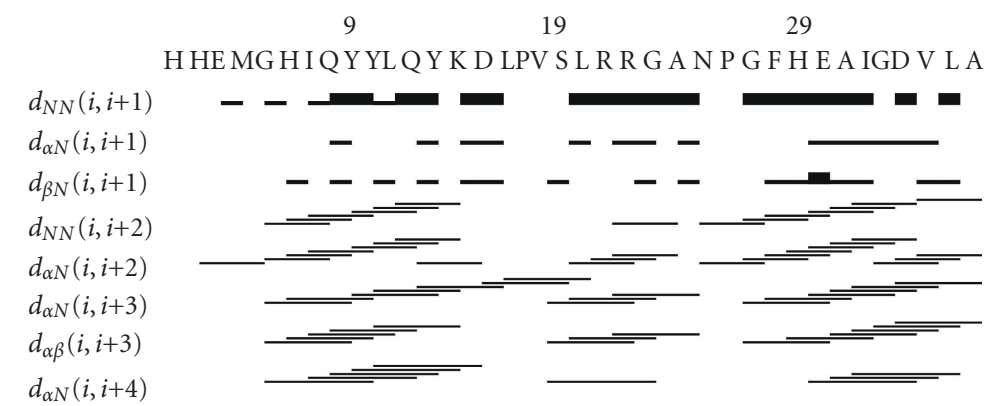

(c)

FIgURE 2: (a) Short-, medium-, and long-range connectivities. (b) Number of NOE constraints per residue (white, gray, dark gray, and black vertical bars represent, resp., intraresidue, sequential, medium-range and long-range connectivities). (c) Schematic representation of the sequential and medium range NOEs involving $\mathrm{HN}, \mathrm{H} \alpha$, and $\mathrm{H}_{\beta}$ protons for $\mathrm{Zn}^{2+}-\mathrm{ACE}_{\mathrm{N}}(37)$ (corresponds to $\mathrm{His}^{360}$-Ala ${ }^{396}$ of the human somatic form).

as possible the structure of the enzyme native active sites are reported. The peptide structures have been determined through circular dichroism and NMR experiments.

The conformational differences of the peptide maquettes representing the two sACE active sites have been also investigated. Moreover, the NMR solution structures of the peptides are being compared to the crystal structure of somatic $\mathrm{ACE}_{\mathrm{N}}$ active site [18] and the testis ACE isoform (tACE) [19] that corresponds to the somatic $\mathrm{ACE}_{\mathrm{C}}$ domain.
In general, we report herein a work, which exploits the potential of peptide chemistry to synthesize polypeptides that represent protein domains or functional fragments and applies a step-by-step investigation strategy able to extract crucial structural data, especially for the metal active sites of enzymes/proteins or others biopolymers, whose biological expression and crystallization are difficult to be acquired, such as GPCRs and highly hydrophobic transmembrane proteins. 


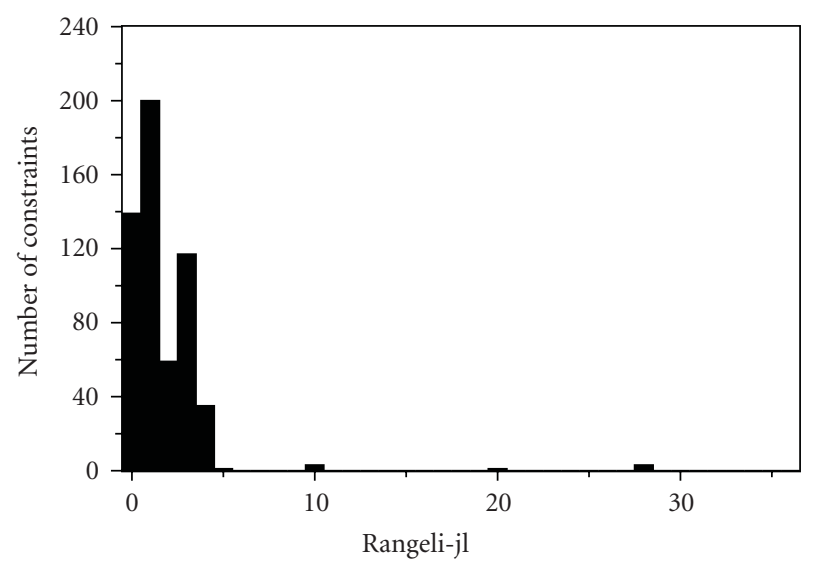

(a)

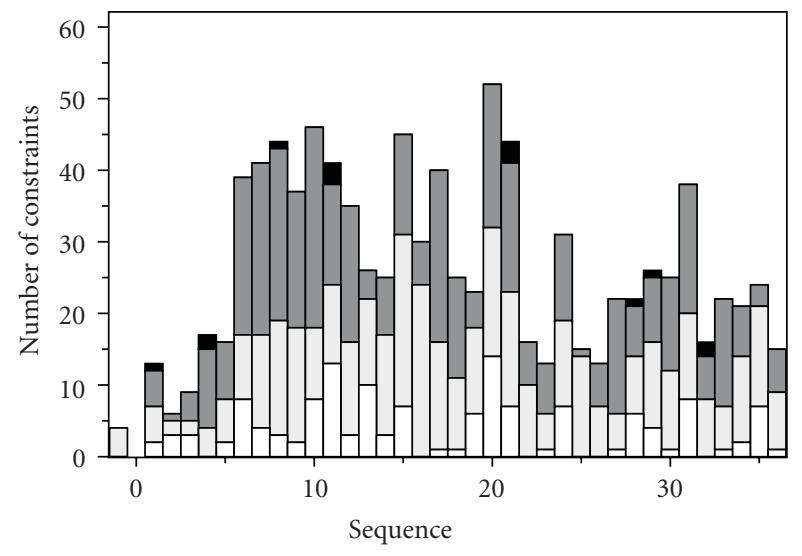

(b)

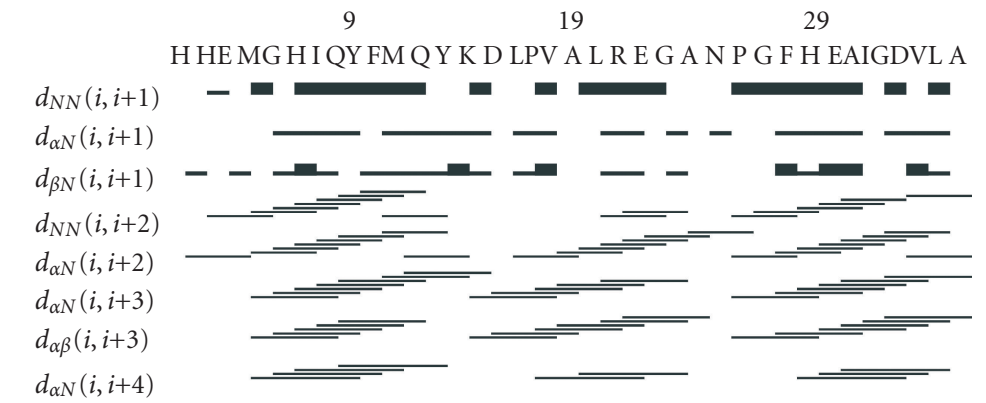

(c)

FIGURE 3: (a) Short-, medium-, and long-range connectivities. (b) Number of NOE constraints per residue (white, gray, dark gray, and black vertical bars represent, resp., intraresidue, sequential, medium-range, and long-range connectivities). (c) Schematic representation of the sequential and medium range NOEs involving $\mathrm{HN}, \mathrm{H} \alpha$, and $\mathrm{H}_{\beta}$ protons for $\mathrm{Zn}^{2+}-\mathrm{ACE}_{\mathrm{C}}$ (37) (corresponds to His ${ }^{958}$-Ala ${ }^{994}$ of the human somatic form).

\section{Materials and Methods}

2.1. Peptide Synthesis. Both peptides representing the domains of the two somatic ACE (sACE) active sites $\operatorname{ACE}_{N}(37)$ : sACE(360-396); $\operatorname{ACE}_{C}(37)$ : sACE(958-994) were synthesized on solid support by $\mathrm{Fmoc} / \mathrm{tBu}$ chemistry, as previously described [15]. Sequence enumeration of the synthetic peptides and the corresponding domains of the human somatic isoform as well as the numbering of the $\mathrm{C}$ (tACE) and $\mathrm{N}$-domain $\left(\mathrm{ACE}_{\mathrm{N}}\right)$ crystal structures are shown in Figure 1.

2.2. Circular Dichroism Experiments. CD experiments were acquired for both $\mathrm{ACE}_{\mathrm{N}}(37)$ and $\mathrm{ACE}_{\mathrm{C}}(37)$ peptides, monitoring the effect of different trifluoroethanol (TFE) concentration, $\mathrm{pH}$ values, and $\mathrm{Zn}^{+2}$ addition on their conformations. Spectra were recorded on a Jasco 710 spectropolarimeter using quartz cells of $1.0 \mathrm{~cm}$ and $0.5 \mathrm{~cm}$ path length, in the far-UV $(200 \mathrm{~nm}-260 \mathrm{~nm})$ at a scanning rate of $100 \mathrm{~nm} / \mathrm{min}$, a time constant of $1 \mathrm{~s}$, and a bandwidth of $1 \mathrm{~nm}$. Spectral resolution was $0.2 \mathrm{~nm}$, and 4 scans were averaged per spectrum.

The concentration used for each sample was 0.3$0.35 \mathrm{mg} / \mathrm{ml}$ of pure peptide in a buffer of $50 \mathrm{mM}$ Tris- $\mathrm{HCl}$ and $200 \mathrm{mM} \mathrm{NaCl}$. The effect of TFE on the peptide conformation was monitored for $0 \%-100 \% \mathrm{TFE}(\mathrm{v} / \mathrm{v}), 25^{\circ} \mathrm{C}$, and $\mathrm{pH}=7.0$. Spectra of different $\mathrm{pH}$ values ranging from 2.6 to 7.0 were recorded for the $\mathrm{Zn}$-containing $\mathrm{ACE}_{\mathrm{N}}(37)$ peptide, at $65 \% \mathrm{TFE}$ and $25^{\circ} \mathrm{C}$. Quantitative evaluation of secondary structure according to the CD data was calculated using the CDNN CD Spectra Deconvolution Program obtained from http://bioinformatik.biochemtech.unihalle .de/cdnn/ [20]. The CD spectra are reported in molar ellipticity as mdeg $\times \mathrm{cm}^{2} / \mathrm{dmol}$ according to molecular masses and peptide length.

2.3. Nuclear Magnetic Resonance Experiments. $5 \mathrm{mg}$ of peptide samples were dissolved in a mixture of $65 \%$ TFE in $\mathrm{H}_{2} \mathrm{O}$, containing $50 \mathrm{mM}$ Tris buffer and $200 \mathrm{mM} \mathrm{NaCl}$. $\mathrm{ZnCl}_{2}$ was added in a slight excess of the peptide equivalents ( $1: 1.1)$ until $0.5 \mathrm{ml}$ final sample volume, with the peptide concentration being approximately $2 \mathrm{mM}$ at $\mathrm{pH}$ value $4.9-$ 5.1 .

Data were acquired at $298 \mathrm{~K}$ on a Bruker Avance $600 \mathrm{MHz}$ spectrometer. ${ }^{1} \mathrm{H} 1 \mathrm{D}$ NMR spectra were recorded using spectral width of $12-17 \mathrm{ppm}$ with or without presaturation of the $\mathrm{H}_{2} \mathrm{O}$ signal. ${ }^{1} \mathrm{H}^{-}{ }^{1} \mathrm{H} 2 \mathrm{D}$ TOCSY $[21,22]$ were recorded using the MLEV-17 spin lock sequence using $\tau_{m}=80 \mathrm{~ms}$. 

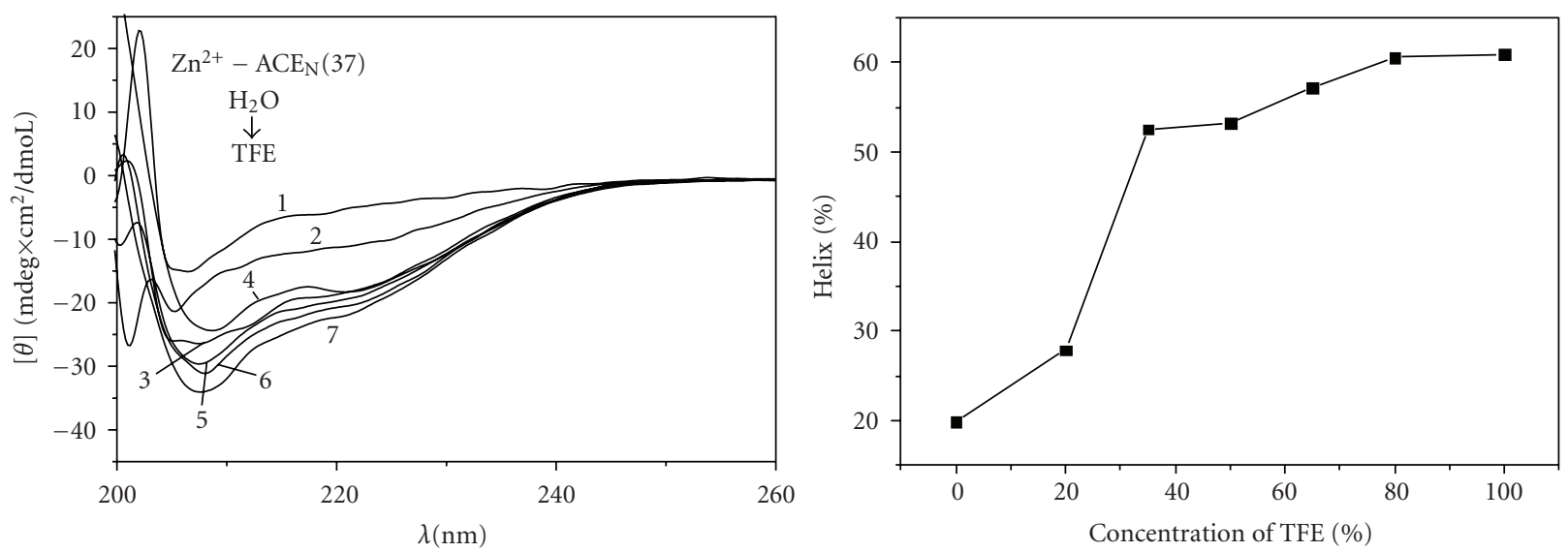

$\begin{array}{ll}\text { 1: } \mathrm{H}_{2} \mathrm{O} & 5: 65 \% \text { TFE } \\ 2: 20 \% \text { TFE } & 6: 80 \% \text { TFE } \\ 3: 35 \% \text { TFE } & 7: \text { TFE } \\ 4: 50 \% \text { TFE } & \end{array}$

(a)


(b)

FIgure 4: Circular dichroism spectra (left) and corresponding diagrams (right) of helical content through data analysis by CDNN software of (a) 2,2,2-trifluoroethanol (TFE) range from $0 \%$ to $100 \%$ of $\mathrm{Zn}^{2+}-\mathrm{ACE}_{\mathrm{N}}$ (37) samples, at $\mathrm{pH}=5.0, \mathrm{~T}=25^{\circ} \mathrm{C}, 50 \mathrm{mM}$ Tris- $\mathrm{HCl}$, and $200 \mathrm{mM} \mathrm{NaCl}$ and (b) of $\mathrm{pH}$ range from 2.6 to 7 of $\mathrm{Zn}^{2+}-\mathrm{ACE}_{\mathrm{N}}(37)$ samples, at $65 \%$ TFE, $T=25^{\circ} \mathrm{C}, 50 \mathrm{mM} \mathrm{Tris-} \mathrm{HCl}$, and $200 \mathrm{mM} \mathrm{NaCl}$.

${ }^{15} \mathrm{~N}$ HSQC and ${ }^{13} \mathrm{C}$ HSQC spectra $[23,24]$ have been recorded at $500 \mathrm{MHz}$ equipped with cryoprobe for $15 \mathrm{~N} / 13 \mathrm{C}$ nuclei in natural abundance. ${ }^{1} \mathrm{H}-{ }^{1} \mathrm{H}$ TPPI NOESY $[25,26]$ spectra were acquired using mixing time $\tau_{m}=200 \mathrm{~ms}$ applying water suppression during the relaxation delay and mixing time. For data processing and spectral analysis, the standard Bruker software (XWIN-NMR 3.5) and XEASY program [27] (ETH, Zurich) were used.

1318 and 1578 NOESY cross-peaks were assigned in both dimensions for $\operatorname{ACE}_{C}(37)$, and $\operatorname{ACE}_{N}(37)$, respectively, in TFE aqueous solution (TFE/ $\left.\mathrm{H}_{2} \mathrm{O} 2: 1\right)$. The number of unique cross-peaks was 753 and 773 for $\operatorname{ACE}_{\mathrm{C}}(37)$ and $\mathrm{ACE}_{\mathrm{N}}(37)$, respectively. Their intensities were converted into upper limit distances through CALIBA [28]. The NOE- derived structural information extracted from the analysis of NOESY spectra acquired in aqueous TFE solutions under identical experimental conditions for both peptides were introduced to DYANA $[29,30]$ software for structure calculation (Figures 2 and 3). Structural calculations have been performed on IBM RISC6000 and xw4100/xw4200 HP Linux workstations. The family ensemble of $\mathrm{Zn}^{2+}-\mathrm{ACE}_{\mathrm{N}}(37)$ peptide presents root mean square deviation (RMSD) values of $0.65 \pm 0.21 \AA$ and $1.25 \pm 0.24 \AA$ for backbone and heavy atoms, respectively, and the average target function was found to be $0.39 \pm 0.0164 \AA^{2}$. The RMSD values of the $\mathrm{Zn}^{2+}$ $\operatorname{ACE}_{C}(37)$ peptide were $0.55 \pm 0.23 \AA$ and $1.04 \pm 0.27 \AA$ for backbone and heavy atoms, respectively, and target function lies in the range $0.60 \pm 4.78 \times 10^{-2} \AA^{2}$. 


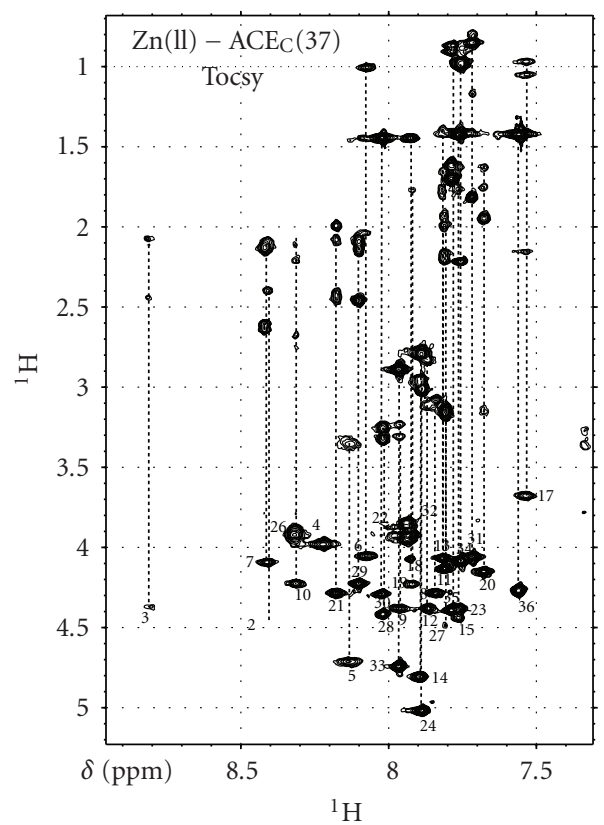

(a)

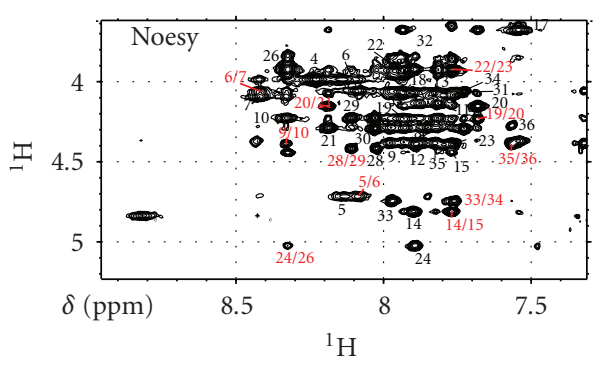

(c)

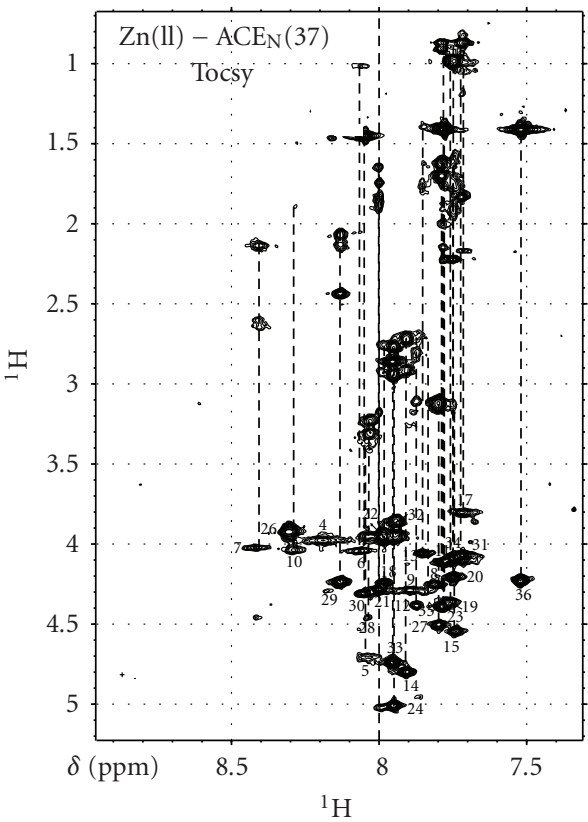

(b)

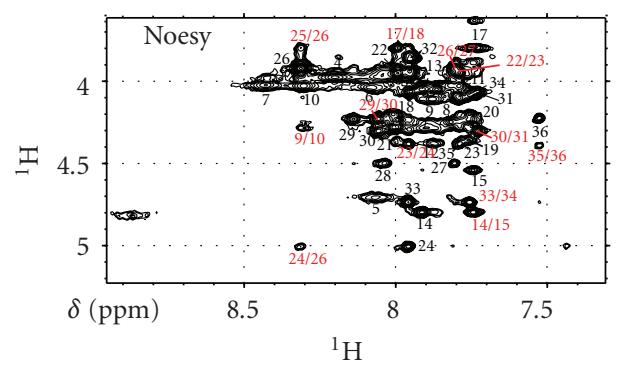

(d)

FIGURE 5: Fingerprint regions of $600 \mathrm{MHz}$ TOCSY ((a) $\operatorname{ACE}_{\mathrm{C}}(37)$ and (b) $\left.\operatorname{ACE}_{\mathrm{N}}(37)\right)$ and NOESY ((c) $\mathrm{ACE}_{\mathrm{C}}(37)$ and (d) $\left.\mathrm{ACE}_{\mathrm{N}}(37)\right)$ spectra recorded at $T=298 \mathrm{~K}$. The sequential connectivity pattern shown indicates the peptide sequence-specific resonance assignment.

\section{Results and Discussion}

3.1. $\alpha$-Helix Content Measurements through Circular Dichroism Data. The Circular Dichroism (CD) experiments provided a qualitative determination of the peptide secondary structure elements in different TFE concentrations, $\mathrm{pH}$ values, and metal addition, leading to the determination of high resolution experimental conditions (Figure 4).

Specifically, the $\mathrm{Zn}^{2+}-\mathrm{ACE}_{\mathrm{N}}(37)$ peptide presents an unfolded structure with low $\alpha$-helical content in aqueous solution. Low TFE concentrations (up to 20\%) do not seem to have major effect on the peptide conformation (Figure 4(a)). However, the CD spectrum of the sample containing 35\% TFE shows two intense minima at 208 and $220 \mathrm{~nm}$, characteristics of $\alpha$-helical structure. Thus, for TFE concentration ranging from $20 \%$ to $35 \%$, an abrupt structural change takes place, leading to a dramatical increase of $\alpha$-helix content from $26 \%$ to $52 \%$. At higher TFE concentrations $(50 \%-100 \%)$, no remarkable alteration of the helical content is noticed. In more detail, the $\alpha$ helical content is increased from $54 \%$ to $60 \%$, for TFE concentration increasing from $50 \%$ to $100 \%$, indicating secondary structure stability of the $\mathrm{Zn}^{2+}-\mathrm{ACE}_{\mathrm{N}}(37)$ peptide at alcohol concentration greater than $50 \%$. Similar results were obtained for the $\mathrm{Zn}^{2+}-\mathrm{ACE}_{\mathrm{C}}$ (37) peptide (data not shown). As a conclusion, the synthetic peptides exhibit a remarkable tendency to adopt helical conformation.

In order to investigate the $\mathrm{pH}$ effect on the $\alpha$-helical content of the $\mathrm{Zn}^{2+}-\mathrm{ACE}_{\mathrm{N}}(37)$ peptide, $\mathrm{CD}$ measurements were performed in $65 \%$ of TFE at $25^{\circ} \mathrm{C}$, at acidic, low acidic, and neutral $\mathrm{pH}$ values. Spectra representing two sets of $\mathrm{pH}$ values nearly overlap, thus suggesting that the secondary structure of ACE peptides exhibit minor differences at these $\mathrm{pH}$ values (Figure 4(b)). In particular, at acidic ( $\mathrm{pH} 2.6$ ) and mild acidic $(\mathrm{pH}$ 4.0) conditions, the Zn-containing $\mathrm{ACE}_{\mathrm{N}}(37)$ solutions possess approximately $48 \% \alpha$-helical content while at $\mathrm{pH}$ values of 5.0 and 7.0 , the helicity of the $\mathrm{ACE}_{\mathrm{N}}(37)$ in the presence of $\mathrm{Zn}^{2+}$ ions is found to be approximately $57.0 \%$.

3.2. NMR Spectra Assignment of $\mathrm{Zn}^{2+}-\mathrm{ACE}_{\mathrm{N}}(37)$ and $\mathrm{Zn}^{2+}$ $A C E_{C}(37)$ Peptides. Thirty-six out of 37 residues of the 
TABle $1:{ }^{1} \mathrm{H},{ }^{15} \mathrm{~N}$, and ${ }^{13} \mathrm{C}$ chemical shifts $(\mathrm{ppm})$ of the residues in the $\mathrm{Zn}^{2+}-\mathrm{ACE}_{\mathrm{N}}(37)$ peptide at $298 \mathrm{~K}(\mathrm{H} 2 \mathrm{O} / \mathrm{TFE}-\mathrm{d} 234 \% / 66 \% \mathrm{v} / \mathrm{v}$. $\mathrm{pH}=$ 4.9).

\begin{tabular}{|c|c|c|c|c|c|c|}
\hline \multicolumn{2}{|c|}{ Residue } & \multirow[t]{3}{*}{$\mathrm{HN} / \mathrm{N}$} & \multirow{3}{*}{$\begin{array}{c}\mathrm{H} \alpha / \mathbf{C} \boldsymbol{\alpha} \\
4.45 \\
\mathbf{5 5 . 3 9}\end{array}$} & \multirow[t]{3}{*}{$\mathrm{H} \beta / \mathbf{C} \beta$} & \multicolumn{2}{|c|}{ Other } \\
\hline \multirow{2}{*}{1} & \multirow{2}{*}{ His } & & & & \multicolumn{2}{|c|}{$\mathrm{H} \delta 2$ 7.30; Нع18.44 } \\
\hline & & & & & C $\delta 120.02$ & CE1 139.44 \\
\hline \multirow{2}{*}{2} & \multirow{2}{*}{ His } & 7.99 & 4.84 & $3.38 / 3.29$ & $\mathrm{H} \boldsymbol{\delta} 2$ 7.32; & $\mathrm{H \varepsilon} 18.45$ \\
\hline & & N 117.01 & 55.84 & 28.45 & C $\delta 2120.05$ & CE1 137.64 \\
\hline \multirow{2}{*}{3} & \multirow{2}{*}{ Glu } & 8.45 & 4.47 & $2.15 / 2.14$ & \multicolumn{2}{|c|}{$\gamma \mathrm{CH}_{3} 2.65 / 2.62$} \\
\hline & & \multirow[t]{3}{*}{ N 121.15} & 56.81 & 31.91 & & 31.90 \\
\hline \multirow{2}{*}{4} & \multirow{2}{*}{ Met } & & 4.35 & $2.13 / 2.09$ & \multicolumn{2}{|c|}{$\mathrm{H} \gamma 2.49 / 2.44$} \\
\hline & & & 57.51 & 33.70 & & 34.78 \\
\hline 5 & Gly & 8.22 & 3.98 & & & \\
\hline$J$ & & N 109.59 & 45.79 & & & \\
\hline 6 & $\mathrm{His}$ & 8.22 & 4.72 & $3.41 / 3.39$ & $\mathrm{H} \delta 2$ 7.26; & $\mathrm{H \varepsilon} 18.50$ \\
\hline 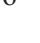 & 1110 & N. 119.31 & 57.08 & 28.57 & C $\delta 119.93$ & Ce1 136.27 \\
\hline 7 & Ile & 8.11 & 4.05 & 2.07 & $\mathrm{H} \gamma 1.70 / 1.32 ; \quad \gamma \mathrm{C}$ & $\mathrm{H}_{3} 1.03 \quad \delta \mathrm{CH}_{3} 0.98$ \\
\hline 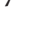 & & N 122.73 & 64.30 & 38.04 & $\mathrm{C} \gamma 128.30 \quad \mathrm{C} \gamma$ & $216.79 \quad \mathrm{C} \delta 12.22$ \\
\hline 8 & $G \ln$ & 8.47 & 4.03 & $2.14 / 2.11$ & $\mathrm{H} \gamma 2.44$ & $\delta \mathrm{NH}_{2} 6.55 / 7.14$ \\
\hline 0 & Gint & N 120.70 & 59.13 & 28.91 & C $\gamma 33.65$ & $\mathrm{~N} \varepsilon 2110.97$ \\
\hline 9 & Tyr & 7.84 & 4.26 & 3.12 & $\mathrm{H} \delta$ 6.96; & Нع 6.75; \\
\hline 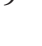 & $1 y_{1}$ & N 120.77 & 60.88 & 38.03 & C $\delta 1133.66$ & Ce1 117.77 \\
\hline 10 & Tyr & 7.87 & 4.29 & $3.26 / 3.22$ & $\mathrm{H} \delta 7.19$ & Нع 6.89; \\
\hline 10 & $1 y_{1}$ & N 120.23 . & 60.82 & 38.11 & C $\delta 1132.73$ & CE1 117.87 \\
\hline 11 & Jep & 8.34 & 4.04 & $1.99 / 1.91$ & $\mathrm{H} \gamma$ 1.53; & $\delta \mathrm{CH}_{3} 0.94$ \\
\hline 11 & Leu & N 119.99 & 57.26 & 41.69 & C $\gamma 28.36$ & C $\delta$ 21.77/24.48 \\
\hline 12 & Gln & 7.81 & 4.11 & $2.01 / 1.91$ & $\mathrm{H} \gamma$ 2.24/2.16; & $\delta \mathrm{NH}_{2} 6.42 / 6.99$ \\
\hline 12 & Uint & N 118.28 & 57.58 & 28.81 & C $\gamma 33.54$ & $\mathrm{~N} \varepsilon 2110.97$ \\
\hline 13 & Tyr & 7.91 & 4.38 & $3.10 / 2.82$ & $\mathrm{H} \delta$ 7.00; & $\mathrm{H \varepsilon} 6.76$ \\
\hline 10 & $1 y_{1}$ & N 120.43 & 59.51 & 35.59 & C $\delta 1132.82$ & Ces1 117.83 \\
\hline 14 & Jys & 7.90 & 4.06 & $1.82 / 1.79$ & $\mathrm{H} \gamma 1.39 ; \quad \delta \mathrm{CH}$ & $1.63 ; \varepsilon \mathrm{CH}_{3} 3.03$ \\
\hline 14 & Lys & N 120.21 & 57.55 & 31.61 & C $\gamma 23.71 \quad$ C $\delta$ & $28.57 \quad \mathrm{C} \varepsilon 42.06$ \\
\hline 15 & Asp & 7.93 & 4.80 & $2.92 / 2.76$ & & \\
\hline & & N 118.92 & 53.56 & 39.48 & & \\
\hline 16 & Leu & 7.76 & 4.54 & 1.79 & $\mathrm{H} \gamma 1.58$ & $\delta \mathrm{CH}_{3} 0.94 / 0.94$ \\
\hline 10 & Leu & 123.89 & 54.95 & 41.64 & C $\gamma 28.43$ & C $\delta$ 23.05/24.36 \\
\hline 17 & Pro & & 4.45 & $2.39 / 1.95$ & $\mathrm{H} \gamma$ 2.02/1.97; & Н $\delta 3.88 / 3.64$ \\
\hline & & & 63.27 & 31.32 & C $\gamma 26.69$ & C $\delta 50.27$ \\
\hline 18 & Val & 7.74 & 3.79 & 2.17 & $\gamma \mathrm{CH}_{3}$ & $1.06 / 1.01$ \\
\hline & val & N 120.40 & 65.07 & 31.81 & $\mathrm{C} \gamma 20$ & $89 / 20.12$ \\
\hline 19 & Ser & 8.02 & 4.23 & $3.99 / 3.95$ & & \\
\hline & & N 116.85 & 60.48 & נים נונים & & \\
\hline 20 & Leu & 7.82 & 4.36 & 1.77 & $\mathrm{H} \gamma$ 1.68; & $\delta \mathrm{CH}_{3} 0.94 / 0.89$ \\
\hline & & N 122.93 & 56.20 & 41.96 & C $\gamma 28.50$ & C $\delta$ 22.29/24.73 \\
\hline 21 & Arg & 7.77 & 4.20 & 1.93 & $\mathrm{H} \gamma$ 1.76/1.65; & H $\delta 3.20 ; \quad$ Нع 7.05 \\
\hline & Ming & N 120.34 & 57.49 & 30.15 & C $\gamma 26.99$ C $\delta$ & $43.13 \quad \mathrm{~N} \varepsilon 135.56$ \\
\hline 22 & Arg & 8.05 & 4.28 & $1.89 / 1.85$ & $\mathrm{H} \gamma$ 1.75/1.64; & $\mathrm{H} \delta 3.17 ; \quad \mathrm{H \varepsilon} 7.15$ \\
\hline 22 & 8 & N 121.00 & 57.05 & 30.14 & C $\gamma 26.92 \quad$ C $\delta$ & $43.07 \quad \mathrm{~N} \varepsilon 135.62$ \\
\hline 23 & Gly & 8.00 & 3.95 & & & \\
\hline & & N 109.07 & 45.43 & & & \\
\hline 24 & Ala & 7.81 & 4.39 & 1.43 & & \\
\hline 24 & Nid & N 124.37 & 52.21 & 19.05 & & \\
\hline 25 & Asn & 7.98 & 5.02 & $2.96 / 2.79$ & $\delta \mathrm{NH}_{2}$ & $6.63 / 7.47$ \\
\hline & 11011 & N 119.26 & 51.13 & 39.17 & $\mathrm{~N} \delta 2$ & 113.31 \\
\hline 26 & Pro & & 4.44 & $2.32 / 1.98$ & $\mathrm{H} \gamma$ 2.07/2.00; & Н $\delta 3.92 / 3.83$ \\
\hline & PTO & & 61.79 & 29.10 & C $\gamma 26.76$ & C $\delta 50.28$ \\
\hline
\end{tabular}


Table 1: Continued.

\begin{tabular}{|c|c|c|c|c|c|}
\hline \multicolumn{2}{|c|}{ Residue } & $\mathrm{HN} / \mathbf{N}$ & $\mathrm{H} \alpha / \mathbf{C} \boldsymbol{\alpha}$ & $\mathrm{H} \beta / \mathrm{C} \boldsymbol{\beta}$ & Other \\
\hline \multirow{2}{*}{27} & \multirow{2}{*}{ Gly } & 8.34 & 3.94 & & \\
\hline & & N 108.58 & 43.10 & & \\
\hline \multirow{2}{*}{28} & \multirow{2}{*}{ Phe } & 7.83 & 4.50 & $3.15 / 3.13$ & $\mathrm{H} \delta 7.25 ; \quad \mathrm{H \varepsilon} 7.29 ; \quad \mathrm{H \zeta} 7.18$ \\
\hline & & N 122.56 & 56.50 & 36.59 & C $\delta$ 130.90/129.60 CE 130.95/129.53 C C 131.21 \\
\hline \multirow{2}{*}{29} & \multirow{2}{*}{ His } & 8.05 & 4.44 & $3.32 / 3.25$ & H $\delta 27.31$ \\
\hline & & N 119.37 & 54.41 & 25.86 & Cع1 139.03 \\
\hline \multirow{2}{*}{30} & \multirow{2}{*}{ Glu } & 8.15 & 4.23 & $2.15 / 2.10$ & $\gamma \mathrm{CH}_{3} 2.45$ \\
\hline & & N 121.57 & 54.73 & 24.95 & C $\gamma 33.54$ \\
\hline \multirow{2}{*}{31} & \multirow{2}{*}{ Ala } & 8.07 & 4.31 & 1.46 & \\
\hline & & N 125.19 & 51.07 & 15.87 & \\
\hline \multirow{2}{*}{32} & \multirow{2}{*}{ Ile } & 7.76 & 4.06 & 1.83 & $\mathrm{H} \gamma$ 1.44/1.18; $\quad \gamma \mathrm{CH}_{3} 0.88 ; \quad \delta \mathrm{CH}_{3} 0.82$ \\
\hline & & N 118.79 & 61.44 & 35.60 & $\begin{array}{lllll}\mathrm{C} \gamma 1 & 27.34 & \mathrm{C} \gamma 2 & 16.84 & \mathrm{C} \delta \\
\delta & 12.08\end{array}$ \\
\hline \multirow{2}{*}{33} & \multirow{2}{*}{ Gly } & 7.96 & $3.95 / 3.87$ & & \\
\hline & & N 110.69 & 43.26 & & \\
\hline \multirow{2}{*}{34} & \multirow{2}{*}{ Asp } & 7.97 & 4.74 & 2.89 & \\
\hline & & N 120.70 & 51.72 & 36.82 & \\
\hline \multirow{2}{*}{35} & \multirow{2}{*}{ Val } & 7.78 & 4.08 & 2.23 & \multirow{2}{*}{$\begin{array}{c}\gamma \mathrm{CH}_{3} 1.00 \\
\mathrm{C} \gamma 20.31 / 24.50\end{array}$} \\
\hline & & N 120.34 & 60.78 & 29.97 & \\
\hline \multirow{2}{*}{36} & \multirow{2}{*}{ Leu } & 7.82 & 4.40 & 1.72 & $\delta \mathrm{CH}_{3} 0.92 / 0.88$ \\
\hline & & N 122.65 & 52.58 & 39.65 & C $\boldsymbol{\delta} 24.16 / 22.01$ \\
\hline \multirow{2}{*}{37} & \multirow{2}{*}{ Ala } & 7.56 & 4.25 & 1.43 & \\
\hline & & N 128.06 & 50.34 & 16.51 & \\
\hline
\end{tabular}

backbone of both $\mathrm{Zn}^{2+}$-ACE peptides have been identified through the analysis of the TOCSY spectra (Figure 5). ${ }^{1} \mathrm{H}$ spin systems of the His, Phe and Tyr aromatic rings were identified with the combined use of $\left[{ }^{1} \mathrm{H}-{ }^{1} \mathrm{H}\right]$ - TOCSY and NOESY spectra (Tables 1 and 2). The two proline residues existing in each construct were found to be at trans conformation for both peptides manifested by strong $\mathrm{H}_{\delta}(\mathrm{i})$ Pro- $\mathrm{H}_{\alpha}(\mathrm{i}-1)$ NOE connectivities.

3.3. NMR Solution Models of $Z^{2+}-A C E_{N}(37)$ \& $Z n^{2+}$ $A C E_{C}$ (37) Peptides. As far as the N-terminal Zn-binding motif of $\operatorname{ACE}_{\mathrm{N}}(37)$ peptide, which contains the two histidyl ligands, is concerned, no definite conformation could be determined due to conformational averaging. A 7-residue fragment close to the $\mathrm{N}$-terminal $\left(\mathrm{Gln}^{8}-\mathrm{Asp}^{15}\right)$ adopts helical structure, which consists partly of an $\alpha$-helix for the 811 fragment and of a short 310 -helix for the rest of the four-residue segment. A second fragment comprised of 7 residues close to peptide $\mathrm{C}$-terminal $\left(\mathrm{His}^{29}\right.$ - Leu ${ }^{36}$ ) adopts a well formed $\alpha$-helical structure. As far as the intermediate fragment of the 23-residue spacer between the two binding motifs is concerned, no helical conformation has been identified. The proximity of the two "active sites helices" is manifested by long-range NOEs concerning backbone and side-chain protons of $\mathrm{His}^{2}-\mathrm{Glu}^{30}, \mathrm{Gly}^{5}-\mathrm{Gly}^{34}, \mathrm{Tyr}^{9}-\mathrm{Phe}^{28}$ see (Figure S1) in Supplementary Material available online at doi: 10.1155/2010/820476, as well as Tyr ${ }^{9}-\mathrm{His}^{30}$ (Figure 6).

The $\mathrm{Zn}^{2+}-\mathrm{ACE}_{\mathrm{C}}(37)$ backbone is characterized by the high content of helical structure. Two helical conformations were observed at both $\mathrm{N}$ - and C-termini, spanning residues
His $^{6}-\mathrm{Lys}^{14}$ and $\mathrm{Phe}^{28}-\mathrm{Val}^{35}$, respectively. Moreover, a $31_{10^{-}}$ helix comprised of a 5-residue segment $\left(\mathrm{Ala}^{19}-\mathrm{Gly}^{23}\right)$ has been identified for the intermediate fragment. In accordance with the $\mathrm{Zn}^{2+}-\mathrm{ACE}_{\mathrm{N}}(37)$ peptide, the two zinc-binding motifs of $\mathrm{Zn}^{2+}-\mathrm{ACE}_{\mathrm{C}}(37)$ are in spatial proximity as manifested by long-range NOEs, such as those between $\mathrm{His}^{6} / \mathrm{Ile}^{7}$ and $\mathrm{His}^{29}$ as well as $\mathrm{Gln}^{8} / \mathrm{Gln}^{12}$ with $\mathrm{Ala}^{19}$ (Figure 7).

3.4. Solution Structure of $\mathrm{Zn}^{2+}-\mathrm{ACE}$ (37) versus $\mathrm{Zn}^{2+}$ $A C E_{C}(37)$. Although the overall fold of the two $\mathrm{Zn}^{2+}$ ACE peptides exhibits significant similarities, some striking differences, mainly related to the helical extent are detected (Figure 8). The double substitution of $\mathrm{Tyr}^{10}$ and $\mathrm{Leu}^{11}$ in $\operatorname{ACE}_{N}(37)$ with $\mathrm{Phe}^{10}$ and $\mathrm{Met}^{11}$ in $\mathrm{ACE}_{\mathrm{C}}(37)$ does not impose any structural change, and the $\alpha$-helix conformation of this segment remains. The nonhelical character of the $\mathrm{N}$-terminal pentapeptide, which comprises the first $\mathrm{Zn}^{2+}$ binding motif, followed by a helical domain of eight to nine residues is conserved in both ACE peptides. However, small differences in NOEs are observed, regarding residues $\mathrm{Ile}^{7}$, $\mathrm{Phe}^{10} / \mathrm{Tyr}^{10}$, and $\mathrm{Leu}^{11} / \mathrm{Met}^{11}$ in $\mathrm{ACE}_{\mathrm{N}}(37)$ and $\mathrm{ACE}_{\mathrm{C}}(37)$ peptide, respectively. Because of the differentiation in position 10, the long range NOEs of the vicinal $\mathrm{Tyr}^{9}$ with $\mathrm{Phe}^{28}$ and $\mathrm{His}^{29}$ that are presented in $\mathrm{ACE}_{\mathrm{N}}(37)$ peptide, are not detected in $\operatorname{ACE}_{C}(37)$. Furthermore, a long-range NOE between $\mathrm{H}_{\varepsilon}$ of $\mathrm{Arg}^{21}$ and $\mathrm{H}_{\varepsilon}$ of $\mathrm{Phe}^{28}$ detected only in $\mathrm{Zn}^{2+}-\mathrm{ACE}_{\mathrm{N}}(37)$ peptide suggests the existence of a loop with the two residues coming close to each other, confirming a tertiary slight structural difference among the two peptides in terms of the orientation of the two zinc-binding motif 
TABle 2: ${ }^{1} \mathrm{H},{ }^{15} \mathrm{~N}$, and ${ }^{13} \mathrm{C}$ chemical shifts $(\mathrm{ppm})$ of the residues in the $\mathrm{Zn}^{2+}-\mathrm{ACE}_{\mathrm{C}}(37)$ peptide at $298 \mathrm{~K}\left(\mathrm{H}_{2} \mathrm{O} / \mathrm{TFE}-\mathrm{d} 234 \% / 66 \% \mathrm{v} / \mathrm{v}\right.$. $\mathrm{pH}=$ 4.9).

\begin{tabular}{|c|c|c|c|c|c|}
\hline & & $\mathrm{HN} / \mathbf{N}$ & $\mathrm{H} \alpha / \mathbf{C} \boldsymbol{\alpha}$ & $\mathrm{H} \beta / \mathrm{C} \boldsymbol{\beta}$ & Other \\
\hline \multirow{2}{*}{1} & \multirow{2}{*}{ His } & & 4.44 & & $\mathrm{H} \delta 2$ 7.34; Hع1 8.48 \\
\hline & & & 55.45 & & C $\boldsymbol{\delta} 2120.14$ C $\varepsilon 1141.76$ \\
\hline \multirow{2}{*}{2} & \multirow{2}{*}{ His } & 7.92 & 4.83 & $3.41 / 3.37$ & $\mathrm{H} \delta 27.31$ \\
\hline & & N 117.71 & 55.86 & 28.53 & C $\boldsymbol{\delta} 2119.85$ \\
\hline \multirow{2}{*}{3} & \multirow{2}{*}{ Glu } & 8.44 & 4.47 & 2.15 & $\gamma \mathrm{CH}_{3} 2.64$ \\
\hline & & N 121.00 & 56.93 & 31.82 & C $\gamma 31.95$ \\
\hline \multirow{2}{*}{4} & \multirow{2}{*}{ Met } & & 4.30 & $2.12 / 2.06$ & $\mathrm{H} \gamma 2.44$ \\
\hline & & & 58.52 & 33.59 & C $\gamma 34.85$ \\
\hline \multirow{2}{*}{5} & \multirow{2}{*}{ Gly } & 8.22 & 3.98 & & \\
\hline & & N 109.22 & 45.83 & & \\
\hline \multirow{2}{*}{6} & \multirow{2}{*}{ His } & 8.22 & 4.69 & 3.39 & $\mathrm{H} \delta 27.25$ \\
\hline & & N.119.42 & 57.33 & 28.64 & C $\delta 2119.79$ \\
\hline \multirow{2}{*}{7} & \multirow{2}{*}{ Ile } & 8.06 & 4.04 & 2.07 & $\mathrm{H} \gamma 1.71 / 1.31 ; \quad \gamma \mathrm{CH}_{3} 1.03 \quad \delta \mathrm{CH}_{3} 0.97$ \\
\hline & & N 122.46 & 64.13 & 38.09 & C $\gamma 128.41 \quad$ C $\gamma 216.81 \quad$ C $\delta 12.18$ \\
\hline \multirow{2}{*}{8} & \multirow{2}{*}{ Gln } & 8.44 & 4.08 & $2.15 / 2.11$ & $\delta \mathrm{NH}_{2} 6.54 / 7.13$ \\
\hline & & N 121.01 & 59.04 & 28.57 & Nع2 110.83 \\
\hline \multirow{2}{*}{9} & \multirow{2}{*}{ Tyr } & 7.90 & 4.27 & 3.12 & $\mathrm{H} \delta$ 6.95; \\
\hline & & N 120.96 & 61.02 & 38.21 & C $\boldsymbol{\delta} \mathbf{1} 132.67$ \\
\hline 10 & Phe & 8.07 & 4.37 & $3.33 / 3.26$ & $\mathrm{H} \delta 7.31 ; \quad \mathrm{H \varepsilon} 7.37 \quad \mathrm{H} \zeta 7.34$ \\
\hline 10 & 10 & N 120.42 & 60.74 & 38.84 & C $\boldsymbol{\delta} 131.03 / 129.50 \quad$ C $\varepsilon$ 131.00/129.43 C \\
\hline 11 & Met & 8.43 & 4.21 & $2.23 / 2.15$ & $\mathrm{H} \gamma 2.79 / 2.72$ \\
\hline 11 & 10 & N 118.65 & 57.43 & 33.58 & C $\gamma 32.35$ \\
\hline 12 & $\mathrm{Gln}$ & 7.81 & 4.14 & $2.00 / 1.90$ & $\delta \mathrm{NH}_{2} 6.40 / 6.70$ \\
\hline 12 & (U110 & N 118.68 & 57.74 & 28.75 & $\mathrm{~N} \varepsilon 2110.86$ \\
\hline 13 & Tyr & 7.92 & 4.38 & $3.13 / 2.82$ & $\mathrm{H} \delta 7.00$ \\
\hline 10 & $1 y^{2}$ & N 120.02 & 59.46 & 39.33 & C $\boldsymbol{\delta} 132.81$ \\
\hline 14 & Lys & 7.85 & 4.05 & $1.78 / 1.81$ & $\mathrm{H} \gamma 1.39 ; \quad \delta \mathrm{CH}_{3} 1.64 ; \quad \varepsilon \mathrm{CH}_{3} 3.05$ \\
\hline & & N 120.09 & 57.76 & 31.58 & C $\gamma 23.68 \quad$ C $\delta 28.76 \quad$ C $\varepsilon 42.19$ \\
\hline 15 & Asn & 7.90 & 4.83 & $2.93 / 2.77$ & \\
\hline 10 & $10 \mathrm{P}$ & N 118.79 & 53.53 & 39.51 & \\
\hline 16 & Leu & 7.78 & 4.46 & 1.79 & $\delta \mathrm{CH}_{3} 0.943 / 0.97$ \\
\hline 10 & Len & 123.98 & 56.77 & 41.25 & C $\delta$ 23.25/24.05 \\
\hline 17 & Pro & & 4.39 & $2.41 / 1.89$ & $\mathrm{H} \gamma$ 2.11/2.07; \\
\hline . & 110 & & 64.61 & 31.21 & C $\gamma 26.79$ \\
\hline 18 & Val & 7.60 & 3.68 & 2.17 & $\gamma \mathrm{CH}_{3} 1.07 / 0.98$ \\
\hline & & N 120.40 & 65.47 & 31.77 & C $\gamma 20.23 / 21.25$ \\
\hline 19 & Ala & 7.94 & 4.08 & 1.46 & \\
\hline & & N 123.38 & 54.68 & 18.08 & \\
\hline 20 & Leu & 7.95 & 4.25 & 1.78 & $\delta \mathrm{CH}_{3} 0.92 / 0.89$ \\
\hline 20 & से & N 123.48 & 56.69 & 41.91 & C $\boldsymbol{\delta} 22.06 / 24.33$ \\
\hline 21 & Arg & 7.70 & 4.15 & 1.96 & $\mathrm{H} \gamma 1.75 / 1.63 ; \quad \mathrm{H} \delta 3.15 ; \quad \mathrm{H \varepsilon} 7.06$ \\
\hline 21 &  & N 120.14 & 57.82 & 30.09 & $\mathrm{C} \gamma 26.80 \quad \mathrm{C} \delta \boldsymbol{\delta} 42.96 \quad \mathrm{~N} \varepsilon 135.38$ \\
\hline 22 & $\mathrm{Glu}$ & 8.23 & 4.30 & $2.10 / 2.00$ & $\gamma \mathrm{CH}_{3} 2.46 / 2.42$ \\
\hline 2 & (1) & N 119.39 & 57.01 & 28.25 & C $\gamma 33.01$ \\
\hline 23 & Gly & 7.95 & 3.93 & & \\
\hline 20 & Wy & N 108.22. & 45.70 & & \\
\hline 24 & Ala & 7.78 & 4.40 & 1.45 & \\
\hline & & N 123.97 & 52.25 & 18.47 & \\
\hline 25 & Asn & 7.90 & 5.03 & $3.03 / 2.81$ & $\delta \mathrm{NH}_{2} 6.61 / 7.50$ \\
\hline & & N 118.78 & 51.01 & 39.09 & N反2 113.04 \\
\hline
\end{tabular}


TABle 2: Continued.



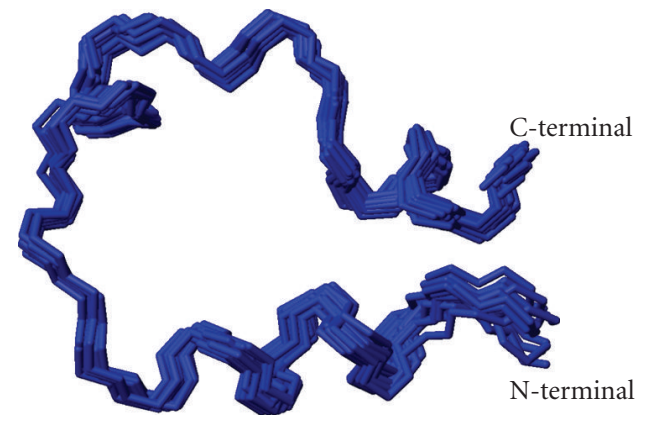

(a)

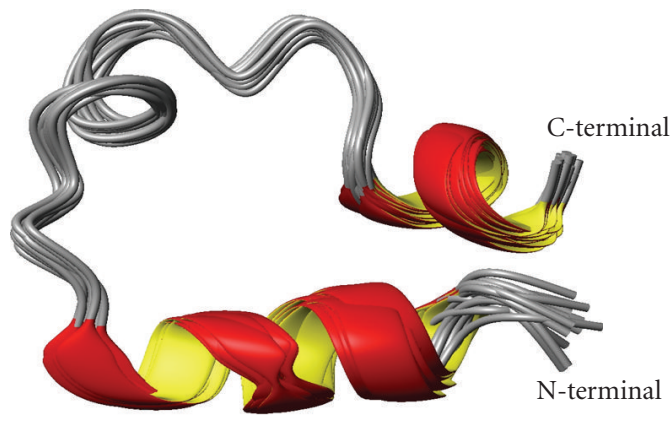

(b)

Figure 6: (a) Ensemble of DYANA 30 best models of the $\mathrm{Zn}^{2+}-\mathrm{ACE}_{\mathrm{N}}(37)$ (corresponds to $\mathrm{His}^{360}$ - $\mathrm{Ala}^{396}$ of the human somatic form) calculated with NMR data. (b) Ribbon diagram of $\mathrm{Zn}^{2+}-\mathrm{ACE}_{\mathrm{N}}(37)$ peptide.

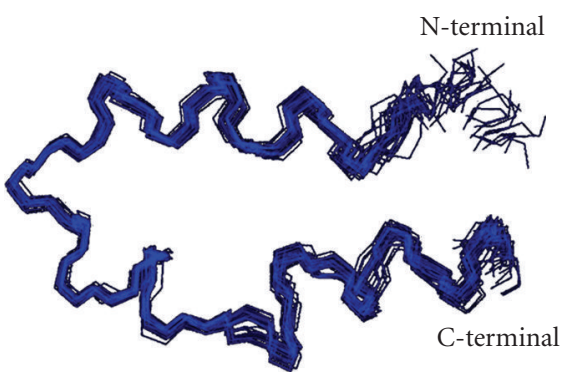

(a)

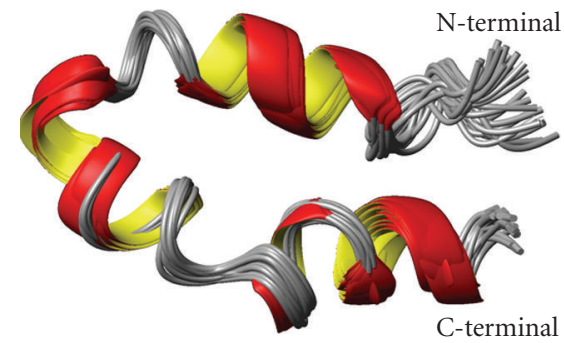

(b)

Figure 7: (a) Ensemble of DYANA 30 best models of the $\mathrm{Zn}^{2+}-\mathrm{ACE}_{\mathrm{C}}$ (37) (corresponds to His ${ }^{958}$ - Ala ${ }^{994}$ of the human somatic form), calculated with NMR data. (b) Ribbon diagram of $\mathrm{Zn}^{2+}-\mathrm{ACE}_{\mathrm{C}}(37)$ peptide. 


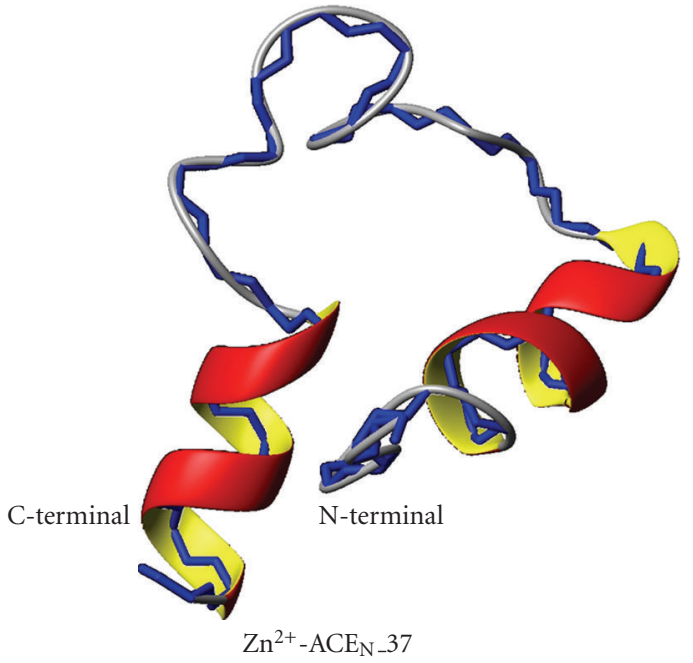

(a)

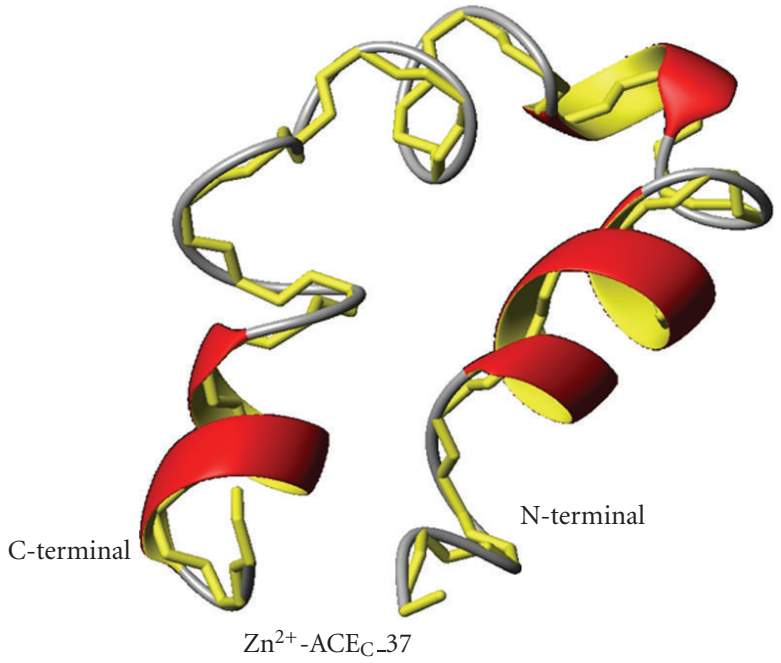

(b)

FIGURE 8: Backbone and ribbon representation of the solution structures of both $\mathrm{Zn}^{2+}-\mathrm{ACE}_{\mathrm{N}}$ (37) (a) (corresponds to His ${ }^{360}-\mathrm{Ala}^{396}$ of the human somatic form) and $\mathrm{Zn}^{2+}-\mathrm{ACE}_{\mathrm{C}}(37)$ (b) (corresponds to His ${ }^{958}$ - Ala ${ }^{994}$ of the human somatic form).

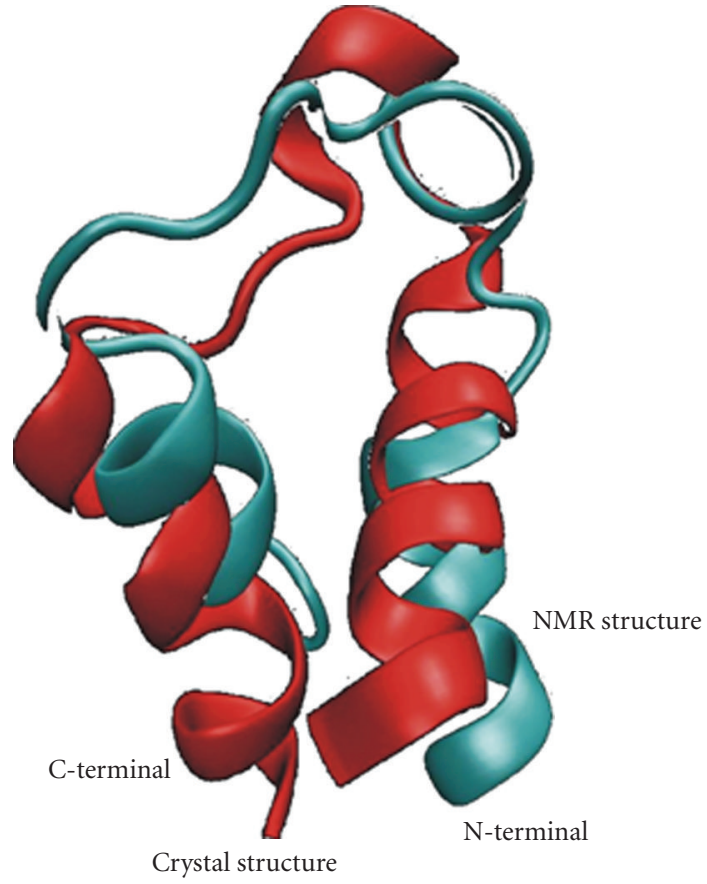

$\mathrm{Zn}^{2+}-\mathrm{ACE}_{\mathrm{N}}-37$

(a)

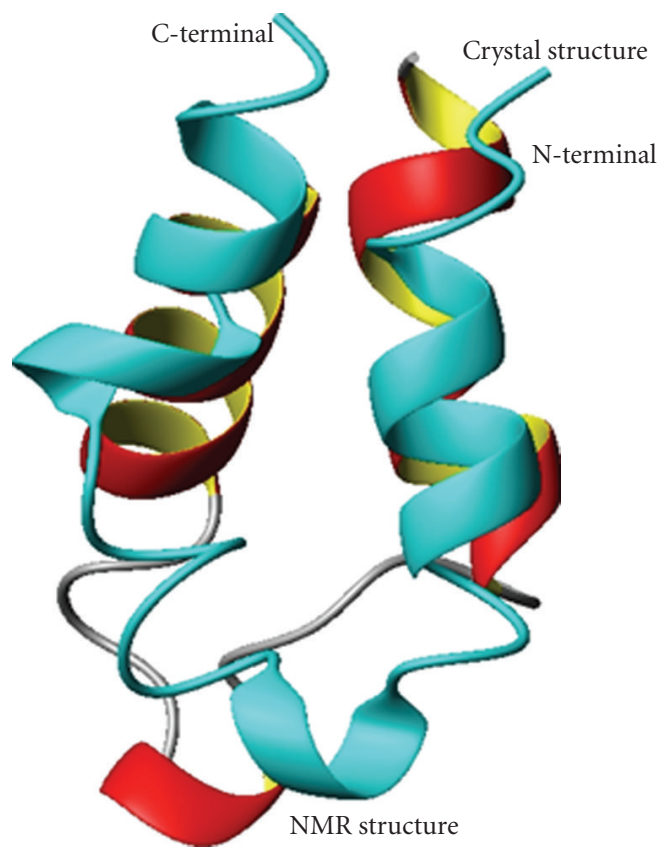

$\mathrm{Zn}^{2+}-\mathrm{ACE}_{\mathrm{C}}-37$

(b)

FIGURE 9: Superimposition of the crystal structure (in red) and the solution structure derived from NMR data (in cyan) of $\mathrm{Zn}^{2+}-\mathrm{ACE}_{\mathrm{N}}(37)$ peptide (a) and $\mathrm{Zn}^{2+}-\mathrm{ACE}_{\mathrm{C}}(37)$ peptide (b).

helices. In $\mathrm{ACE}_{\mathrm{C}}(37)$ peptide, the two side chains of these residues are oriented almost parallel to each other pointing though to opposite orientation providing a more "extended" conformation for this segment. Additionally, a helix of the C-termini is observed in both peptides.

The substitutions of the amino acids at positions 19 $\left(\mathrm{Ser}^{19} / \mathrm{Ala}^{19}\right)$ and $22\left(\mathrm{Arg}^{22} / \mathrm{Glu}^{22}\right)$ of the peptide sequence seem to differentiate the structure of the two peptides. The most important diversity among the structures of the $\mathrm{ACE}_{\mathrm{N} / \mathrm{C}}$ peptides regards the 5-residue spanning $\alpha$-helix $\left(\mathrm{Ala}^{19}-\mathrm{Gly}^{23}\right)$ of the intermediate spacer between the two zinc-binding motifs, detected only in the $\operatorname{ACE}_{\mathrm{C}}(37)$ peptide. The absence of the intermediate helix in the $\operatorname{ACE}_{\mathrm{N}}(37)$ peptide probably provides a less constrained domain to the 
$\mathrm{N}$-active site of the somatic form in a crucial socket region for the substrate binding. As a conclusion, the presence or absence of the helical structure of the intermediate spacer determines the relative position of the two terminal helices and differentiates the active-site cavity structure and volume, where the substrate is accommodated. Both active sites of the somatic form act as carboxy dipeptidase, hydrolyzing the amide bond and releasing the C-terminal dipeptide from a native substrate [1]. Additionally, only the $\mathrm{ACE}_{\mathrm{N}}$ domain presents endopeptidase activity, by releasing the C-terminal tripeptide of the $\mathrm{GnRH}$ hormone and the tetrapeptide of the native octapeptide Enkephalin [12]. Accommodation of these peptides in active or not mode for proteolytic cleavage, might be influenced by the conformation of the interhelical spacer.

3.5. NMR Solution Structure versus X-Ray. The overall fold of both synthetic peptides solution structures presents high similarity to the corresponding domain of the crystal structure of the testis ACE isoform [19] (tACE has identical sequence with the $\mathrm{C}$-domain of the ACE somatic isoform) and the somatic $\mathrm{ACE}_{\mathrm{N}}$ domain [18]. Minor differences exist regarding the length of the helices at the termini of the peptides (Figure 9). The backbone RMSD value for the family of $20 \mathrm{NMR}$ structures of the $\mathrm{ACE}_{\mathrm{N}}$ peptide and the crystal structure $(2 \mathrm{C} 6 \mathrm{~F})$ was found to be $1.42 \AA$ and the corresponding RMSD value calculated for the mean NMR structure and the X-ray structure was found to be $3.802 \AA$. The backbone RMSD value for the family of 20 NMR structures of the $\mathrm{ACE}_{\mathrm{C}}$ peptide and the crystal structure (1O8A) was found to be $0.775 \AA$ and the corresponding RMSD value calculated for the mean NMR structure and the $\mathrm{X}$-ray structure was found to be $3.595 \AA$.

In the tACE X-ray structure, two helical fragments are present at the $\mathrm{N}$ - and $\mathrm{C}$ - terminal, both comprising a 12residue segment (Figure 9). For $\mathrm{ACE}_{\mathrm{N}}$ crystal structure the $\mathrm{N}$-terminal 13-residue fragment exhibits a helical conformation, as well as the entire C-terminal 12-residue fragment (Figure 9(a)). Regarding the intermediate spacer among the two zinc-binding motifs, an additional helix region consisting of 3 amino acids is present at both tACE and $\mathrm{ACE}_{\mathrm{N}}$ $\mathrm{X}$-ray structures. In the case of the NMR derived structure, a shorter helical fragment has been observed for both termini. The obtained data for the $\mathrm{Zn}^{2+}-\mathrm{ACE}_{\mathrm{N}}(37)$ suggest that as far as the $\mathrm{N}$-terminal is concerned a 10-residue fragment $\left(\mathrm{His}^{6}-\mathrm{Asp}^{15}\right.$ ) and as far as the C-terminal is concerned a 8residue fragment $\left(\mathrm{His}^{29}\right.$-Leu $\left.{ }^{36}\right)$ exhibit helical conformation. Similar results have been obtained for the synthetic peptide representing the C-catalytic domain of the human somatic form and the corresponding domain of the testis form. Differences among the ACE catalytic site maquettes and Xray structures might be due to the fact that the native $\mathrm{N}$ and C-domains exhibit compact structures, and packing of the structure elements in the interior of the enzyme where the catalytic center is cited diminishes the conformational flexibility of the two active-site helices.

Concerning the intermediate spacer between the two zinc-binging motifs, the X-ray models present an additive 3-residue helical segment residue, concerning residues 1820 (numbering of crystal structure: tACE: $\mathrm{Val}^{399}-\mathrm{Leu}^{401}$; $\left.\mathrm{ACE}_{\mathrm{N}}: \mathrm{Val}^{377}-\mathrm{Leu}^{379}\right)$. NMR solution structure of the $\mathrm{Zn}^{2+}$ $\operatorname{ACE}_{C}(37)$ peptide resulted in significantly similar conformation. At $\mathrm{ACE}_{\mathrm{C}}(37)$ peptide, a $33_{10}$ helix is formed for the 5-residue segment $\mathrm{Ala}^{19}-\mathrm{Gly}^{23}$. Instead, no helical conformation has been detected for the $\mathrm{Zn}^{2+}-\mathrm{ACE}_{\mathrm{N}}(37)$ peptide, according to the NMR data and the DYANA calculations. However, both structures of tACE and $s \mathrm{ACE}_{N}$ have been further solved in complex with the typical ACE inhibitor, lisinopril [19] (Figures S2 and S3). Among them, a helical structure is identified for the intermediate spacer only in the tACE-lisinopril structure, while in the $\mathrm{sACE}_{\mathrm{N}}$-lisinopril model the helical segment is absent. The modifications of positions 19 and 22 in the $\mathrm{sACE}_{\mathrm{N}}$ peptide are probably playing an important role in the structural diversity of the spacer and are consequently crucial for the different activity and substrate specificity of these two active sites.

As a conclusion, the conformation of the synthetic peptides and the orientation of the two helical motifs upon zinc coordination are remarkably similar to the native structure, indicating the ACE catalytic site maquettes as reliable models of the enzyme active centre. The detected differences are clearly depended on the physicochemical properties of the peptides in solution compared to the crystal structures.

\section{Conclusions}

NMR studies of the synthetic peptides generated structures that successfully simulate the crystal structures of ACE Cand $\mathrm{N}$-domains. Circular dichroism experiments provided important data, compensate not only for experimental conditions of the NMR analysis, but also for the elucidation of the structural characteristics of the two peptides, corresponding to the two somatic isoform ACE catalytic sites domains. The TFE use in aqueous mixtures, the proper $\mathrm{pH}$ value, as well as the presence of the $\mathrm{Zn}$-ion create a solution environment, in which peptides adopt a similar fold to the native structure. The NMR data and the computational analysis led to structural models of the peptides, which are in great agreement with the X-ray structures. The secondary structure features of the peptides that correspond to the sequence of the ACE catalytic sites $\mathrm{X}$-ray structures $\mathrm{Zn}^{2+}-\mathrm{ACE}_{\mathrm{N}}(37)$ to $\mathrm{ACE}_{\mathrm{N}} ; \mathrm{Zn}^{2+}-\mathrm{ACE}_{\mathrm{C}}(37)$ to tACE present minor differences compared to the crystal structures. Furthermore, the ACE maquettes and the X-ray structures present significant similarities in the orientation of the active site helices, in respect of the position of the zinc ligands for metal coordination. On the other hand, the peptide representing the $\mathrm{N}$-catalytic site lacks the helix of the intermediate region. Thus, the two terminal helices of the $\mathrm{C}$ catalytic site maquette are found closer than those in $\mathrm{ACE}_{\mathrm{N}}$, illustrating potential differences into the catalytic site pocket for substrate selectivity, binding, and accommodation. This crucial difference might possibly explain the functional diversity of the two somatic isoforms of the human ACE. This approach might be helpful in the reconstitution of 
other enzymes' active sites with unknown structures. In gluzincins, the spacer among the two zinc-binding motifs is regarded as of great importance for the specificity of the native substrates and external ligands, such as inhibitors. As far as somatic ACE is concerned, both active sites exhibit carboxy dipeptidase function while only the $\mathrm{N}$-catalytic site exhibits also endopeptidase activity.

In the work reported here, crucial structural data for solution conformations have been extracted even though the crystal structure of testis ACE has been solved. Due to the functional diversity of the two ACE active sites, the "structure-based drug design" of the next generation of pharmaceutical agents, which specifically inhibit one of the two zinc catalytic domains of somatic ACE, is of major importance for the preferential modulation of ACE proteolytic activity towards a more effective treatment of hypertensive patients.

\section{Abbreviations}

$\begin{array}{ll}\text { ACE: } & \text { Angiotensin-I Converting Enzyme } \\ \text { sACE: } & \text { ACE somatic isoform } \\ \text { tACE: } & \text { ACE testis isoform } \\ \text { ACE }_{\mathrm{N}}: & \text { N-domain of sACE } \\ \text { ACE }_{\mathrm{C}}: & \text { C-domain of sACE } \\ \text { TFE: } & \text { 2,2,2-trifluoroethanol } \\ \text { DQF-COSY: } & \text { Double-quantum-filtered phase-sensitive } \\ & \text { correlated spectroscopy } \\ \text { Tris: } & \text { Tris(hydroxymethyl)aminomethane } \\ \text { TOCSY: } & \text { Total Correlated Spectroscopy } \\ \text { NOE: } & \text { Nuclear Overhauser effect } \\ \text { NOESY: } & \text { Nuclear Overhauser effect spectroscopy } \\ \text { TPPI: } & \text { Time-proportional phase incrementation } \\ \text { WATERGATE: } & \text { Water suppression by gradient-tailored } \\ & \text { excitation } \\ \text { RMSD: } & \text { Root Mean Square Deviation } \\ \text { REM: } & \text { Restrained Energy Minimization } \\ \text { GPCRs: } & \text { G-protein coupled receptors. }\end{array}$

\section{Acknowledgments}

G. A. Spyroulias and Z. Spyranti wish to thank EUNMR program Grant RII3-026145 (Center of Magnetic Resonance no. (CERM), University of Florence) for access to NMR instrumentation. G. A. Spyroulias also acknowledges a short-term EMBO grant (ASTF 53.00-03). Z. Spyranti and A. S. Galanis contributed equally to this work. Dr. Maria Pelekanou is also acknowledged for assistance in CD measurements.

\section{References}

[1] R. L. Soffer, "Angiotensin converting enzyme and the regulation of vasoactive peptides," Annual Review of Biochemistry, vol. 45, pp. 73-94, 1976.

[2] E. G. Erdos, "Angiotensin I converting enzyme and the changes in our concepts through the years," Hypertension, vol. 16, no. 4, pp. 363-370, 1990.
[3] H. Gavras, "Angiotensin converting enzyme inhibition and its impact on cardiovascular disease," Circulation, vol. 81, no. 1, pp. 381-388, 1990.

[4] The Heart Outcomes Prevention Evaluation Study Investigators, "Effects of an angiotensin-converting-enzyme inhibitor, ramipril, on cardiovascular events in high-risk patients," New England Journal of Medicine, vol. 342, pp. 145-153, 2000.

[5] PEACE Trial Investigators, "Angiotensin-converting-enzyme inhibition in stable coronary artery disease," New England Journal of Medicine, vol. 351, no. 20, pp. 2058-2068, 2004.

[6] T. Inagami, “The renin-angiotensin system," Essays in Biochemistry, vol. 28, pp. 147-164, 1994.

[7] M. A. Ondetti and D. W. Cushman, "Enzymes of the reninangiotensin system and their inhibitors," Annual Review of Biochemistry, vol. 51, pp. 283-308, 1982.

[8] A. Roks, H. Buikema, Y. M. Pinto, and W. H. van Gilst, "The renin-angiotensin system and vascular function. The role of angiotensin II, angiotensin-converting enzyme, and alternative conversion of angiotensin I," Heart and Vessels, vol. 12, pp. 119-124, 1997.

[9] P. Bunning, B. Holmquist, and J. F. Riordan, "Substrate specificity and kinetic characteristics of angiotensin converting enzyme," Biochemistry, vol. 22, no. 1, pp. 103-110, 1983.

[10] M. R. W. Ehlers, E. A. Fox, D. J. Strydom, and J. F. Riordan, "Molecular cloning of human testicular angiotensinconverting enzyme: the testis isozyme is identical to the Cterminal half of endothelial angiotensin-converting enzyme," Proceedings of the National Academy of Sciences of the United States of America, vol. 86, no. 20, pp. 7741-7745, 1989.

[11] A.-L. Lattion, F. Soubrier, J. Allegrini, C. Hubert, P. Corvol, and F. Alhenc-Gelas, "The testicular transcripts of the angiotensin I-converting enzyme encodes for the ancestral, non-duplicated form of the enzyme," FEBS Letters, vol. 252, no. 1-2, pp. 99-104, 1989.

[12] M. R. W. Ehlers and J. F. Riordan, "Angiotensin-converting enzyme: zinc- and inhibitor-binding stoichiometries of the somatic and testis isozymes," Biochemistry, vol. 30, no. 29, pp. 7118-7126, 1991.

[13] M. J. Rieder, S. L. Taylor, A. G. Clark, and D. A. Nickerson, "Sequence variation in the human angiotensin converting enzyme," Nature Genetics, vol. 22, no. 1, pp. 59-62, 1999.

[14] N. M. Hooper, "Families of zinc metalloproteases," FEBS Letters, vol. 354, no. 1, pp. 1-6, 1994.

[15] G. A. Spyroulias, A. S. Galanis, G. Pairas, E. ManessiZoupa, and P. Cordopatis, "Structural features of angiotensinI converting enzyme catalytic sites: conformation studies in solution, homology models and comparison with other zinc metallopeptidases," Current Topics in Medicinal Chemistry, vol. 4, no. 4, pp. 403-429, 2004.

[16] A. S. Galanis, G. A. Spyroulias, R. Pierattelli, et al., "Zinc binding in peptide models of angiotensin-I converting enzyme active sites studied through ${ }^{1} \mathrm{H}-\mathrm{NMR}$ and chemical shift perturbation mapping," Biopolymers, vol. 69, no. 2, pp. 244252, 2003.

[17] A. S. Galanis, G. A. Spyroulias, G. Pairas, E. Manessi-Zoupa, and P. Cordopatis, "Solid-phase synthesis and conformational properties of angiotensin converting enzyme catalytic-site peptides: the basis for a structural study on the enzymesubstrate interaction," Biopolymers, vol. 76, no. 6, pp. 512-526, 2004.

[18] H. R. Corradi, S. L. U. Schwager, A. T. Nchinda, E. D. Sturrock, and K. R. Acharya, "Crystal structure of the N domain of 
human somatic angiotensin I-converting enzyme provides a structural basis for domain-specific inhibitor design," Journal of Molecular Biology, vol. 357, no. 3, pp. 964-974, 2006.

[19] R. Natesh, S. L. U. Schwager, E. D. Sturrock, and K. R. Acharya, "Crystal structure of the human angiotensinconverting enzyme-lisinopril complex," Nature, vol. 421, no. 6922, pp. 551-554, 2003.

[20] G. Bohm, R. Muhr, and R. Jaenicke, "Quantitative analysis of protein far UV circular dichroism spectra by neural networks," Protein Engineering, vol. 5, no. 3, pp. 191-195, 1992.

[21] L. Braunschweiler and R. R. Ernst, "Coherence transfer by isotropic mixing: application to proton correlation spectroscopy," Journal of Magnetic Resonance, vol. 53, no. 3, pp. 521-528, 1983.

[22] A. Bax and D. G. Davis, "MLEV-17-based two-dimensional homonuclear magnetization transfer spectroscopy," Journal of Magnetic Resonance, vol. 65, no. 2, pp. 355-360, 1985.

[23] A. D. Bax and S. Grzesiek, "Methodological advances in protein NMR," Accounts of Chemical Research, vol. 26, no. 4, pp. 131-138, 1993.

[24] A. G. Palmer III, J. Cavanagh, P. E. Wright, and M. Rance, "Sensitivity improvement in proton-detected twodimensional heteronuclear correlation NMR spectroscopy," Journal of Magnetic Resonance, vol. 93, no. 1, pp. 151-170, 1991.

[25] D. Marion and K. Wüthrich, "Application of phase sensitive two-dimensional correlated spectroscopy (COSY) for measurements of ${ }^{1} \mathrm{H}-{ }^{1} \mathrm{H}$ spin-spin coupling constants in proteins," Biochemical and Biophysical Research Communications, vol. 113, no. 3, pp. 967-974, 1983.

[26] J. Jeener, B. H. Meier, P. Bachmann, and R. R. Ernst, "Investigation of exchange processes by two-dimensional NMR spectroscopy," Journal of Chemical Physics, vol. 71, no. 11, pp. 4546-4553, 1979.

[27] C. Eccles, P. Güntert, M. Billeter, and K. Wüthrich, "Efficient analysis of protein 2D NMR spectra using the software package EASY," Journal of Biomolecular NMR, vol. 1, no. 2, pp. 111-130, 1991.

[28] P. Güntert, W. Braun, and K. Wüthrich, "Efficient computation of three-dimensional protein structures in solution from nuclear magnetic resonance data using the program DIANA and the supporting programs CALIBA, HABAS and GLOMSA," Journal of Molecular Biology, vol. 217, no. 3, pp. 517-530, 1991.

[29] P. Güntert, C. Mumenthaler, and K. Wüthrich, "Torsion angle dynamics for NMR structure calculation with the new program DYANA," Journal of Molecular Biology, vol. 273, no. 1, pp. 283-298, 1997.

[30] K. Wüthrich, M. Billeter, and W. Braun, "Pseudo-structures for the 20 common amino acids for use in studies of protein conformations by measurements of intramolecular protonproton distance constraints with nuclear magnetic resonance," Journal of Molecular Biology, vol. 169, no. 4, pp. 949-961, 1983. 


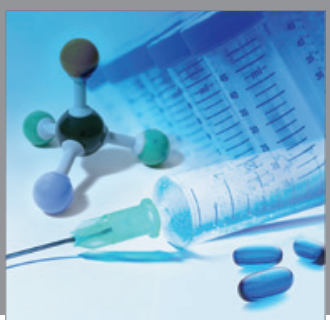

International Journal of

Medicinal Chemistry

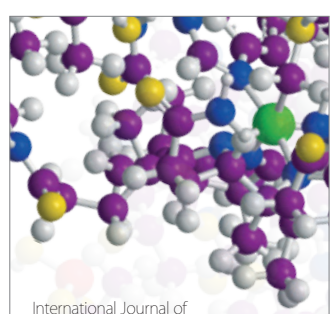

Carbohydrate Chemistry

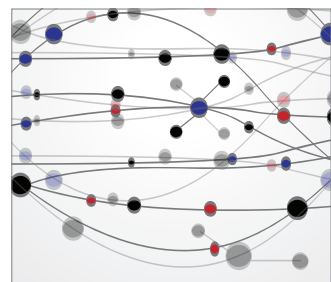

The Scientific World Journal
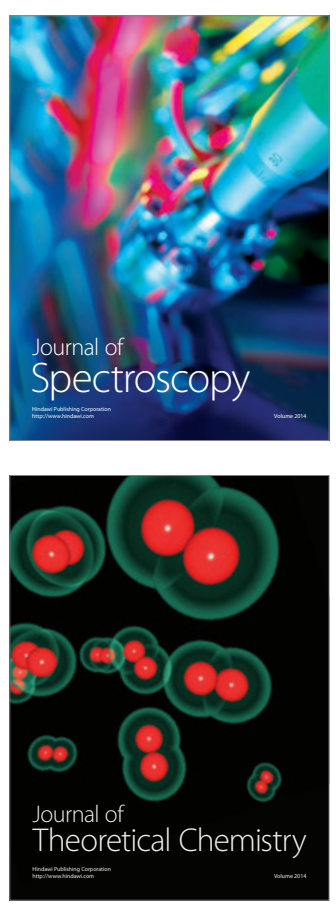
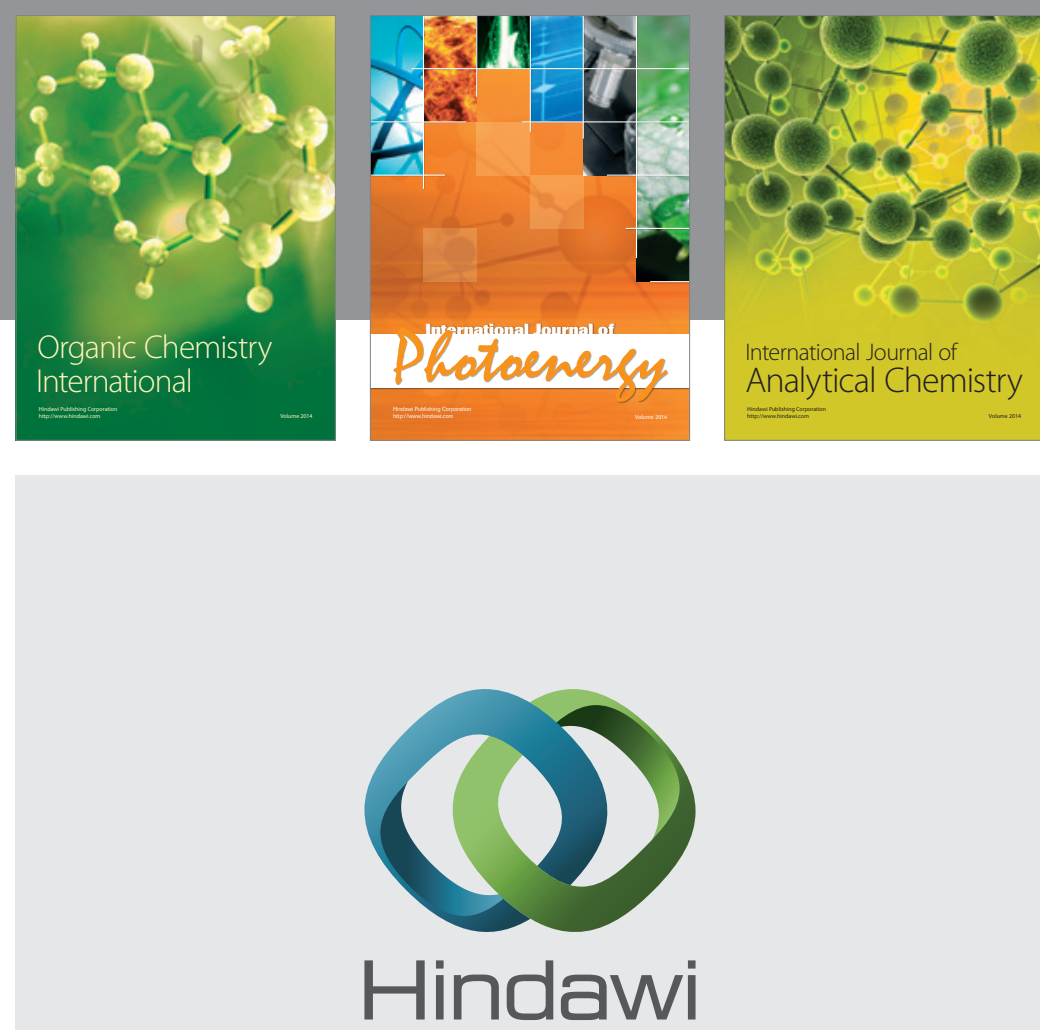

Submit your manuscripts at

http://www.hindawi.com
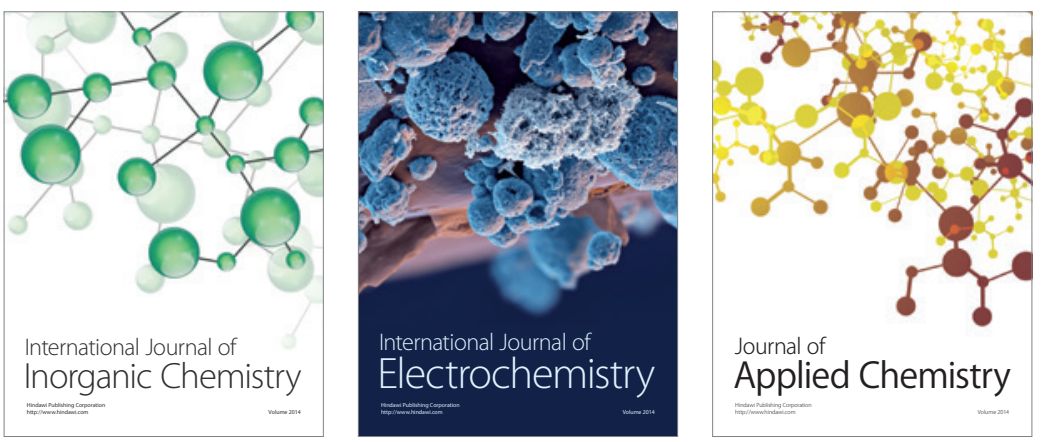

Journal of

Applied Chemistry

